\title{
BUSINESS PLANNING AND PERFORMANCE OF SMALL AND MEDIUM ENTERPRISES IN ANAMBRA STATE
}

\author{
Chime, Francisca Uzoamaka \\ Department of Business Administration, Faculty of Management Sciences, \\ Nnamdi Azikiwe University, Awka, Anambra State Nigeria.
}

Article DOI: https://doi.org/10.36713/epra7825

DOI No: 10.36713/epra7825

\begin{abstract}
The growing significance of SMEs cannot be overemphasized in view of its contributions to the economic growth of the State through employment. The major objective of this study is to establish the relationship between Business Planning and the Performance of SMEs in Anambra State. The specific objectives are: to examine the relationship between benchmarking and earned income of the operators of SMEs in Anambra State; to ascertain the relationship between brand identity and deduction for goods returned to SMEs operators in Anambra State and to determine the relationship between accuracy of the action plan and discounts in SMEs in Anambra State. The study was anchored on McClland's theory of needs, goal setting theory, social and recognition theories. Three research questions and Hypotheses which are in line with the objectives guided the study. The study adopted survey research design. Both primary and secondary data were used to carry out the study. A five point Likert scale structured questionnaire was used in collecting data. A sample size of 400 was obtained through the use of Taro Yamane and Pearson's Product Moment Correlation Coefficient was used to test the hypotheses. Findings from the test of hypotheses carried out indicates that there is a strong positive and significant relationship between benchmarking and earned income; that there is a significant relationship between brand identity and deductions for goods returned; finally, there is a significant positive relationship between accuracy of the action plan and discounts in SMEs. Since there is a positive strong relationship between decomposed variables of the independent and dependent variables then we concluded that business planning plays a crucial role in determining the performance of SMEs. The researcher recommends among others that every SMEs need to embrace business planning for effective performance.
\end{abstract}

\section{INTRODUCTION}

\section{Background of the Study}

Business in Nigeria has been classified as Small, Medium and large (Ayozie, Oboreh, Unukoro \& Ayozie 2013). In both the developed and developing countries the government is turning to small and medium industries as a means of economic development and a veritable means of solving problems. It is also seen as a seedbed of innovations, inventions and employment. Ayozie (2013) states that Small and Medium Enterprises (SMEs) assist in promoting the growth of the country's economy hence the need for business to actively respond to environmental challenges has become imperative as it offers business firms a competitive edge in today's business world. Based on this premises every business organization regardless of its size must have some form of business plan and adherence to its processes in order to overcome every business challenges or pit falls. Business planning process is used by management to establish goals, schedule activities for achieving those goals and include methods for measuring progress. SMEs are expected to play an increasing role in a country's socioeconomic development and the quality of the SMEs is very critical in the economic development of the state or nation at large.

In view of the above, small and medium scale enterprises operate within the economic environment characterized by volatility, dynamism and competitive markets that may seriously threaten their survival. The operating environment for SMEs is constantly changing in face of a volatile economic environment and a highly competitive market. For SMEs to stand firm inspite of volatility and competitive environment it needs to engage in effective business planning process. Unstable and competitive environments require increased planning capability and comprehensiveness, as well as greater planning flexibility. Business planning is used as a weapon to cushion SMEs against the unstable business 
environment in order to ensure their survival and growth. Though, some SMEs operators are ignorant of it, which are reasons for their poor performance as a result of lack of or inadequate business planning. Based on this, this study set out to carry out the research on some selected small enterprises in Anambra State.

Plan will prove the strength or weakness of the organization thereby enabling them to invest/lend money to the SME or refrain from it. Also, information from some of their staff is very important in preparing the business plan. The need for business planning is vital in emerging economies like Nigeria where the business environment seems unstable, business cycles alter and competition is tightening. From the point of view of the changing business environment, planning can also be a continuous process, because changes in business environment are continuous. The idea here is not that plan must be changed in accordance with changing factors of the business environment; rather it means that planning must be continuous because commitments once made become fruitful over a short period of time.

Planning can be conceived as the process by which managers set objectives, assess the future, and develop courses of action designed to accomplish these objectives. The planning processes actually include the determination of appropriate goals and objectives and the optimum timetable for achieving them. Business planning therefore is the process of determining a commercial enterprise's objectives, strategies and projected actions in order to promote its survival and development within a given time frame. An effective business plan supports organization's growth, helps to manage cash flow and develops the course of action. Apart from that it provides honest evaluation of firm's strengths and weaknesses, states clearly the vision and mission and follows the performance (Ashe-Edmunds 2016; Gleeson 2016). An organization's business plan is an overall game plan which management uses to position the business for success in its chosen target market, compete effectively, maximize customer satisfaction and deliver superior value to all its stakeholders over a period of time usually one to five years. In view of this SMEs often implement business planning to improve organizational productivity.

Small and medium enterprises (SMEs) are vital components in economic development in countries around the world. They contribute significantly to economic development, but in some cases they are susceptible to poor performance and ultimately collapse basically because of lack of effective planning before commencing the enterprise (Nkwe 2012). Also, few entrepreneurs who managed to plan before starting their businesses fail to follow the principles as stated in the plan they prepared for their businesses or abandon it entirely. This means that business without a solid plan is bound to fail. Based on the above, business planning in the course of starting-up any business venture or nurturing existing one is very important because business planning is the life wire of every business to achieve increase profitability, stability, market share and sales growth.

Anambra state is one of the South-Eastern states in Nigeria, is a state highly dominated by business men and women. SMEs assist in promoting the growth of Anambra State's economy and that of Nigeria in general. Presently, according to Ayozie (2013), all the levels of government at different times have policies which promote the growth and substance of SMEs. Despite these policies and the aim for enacting them there still exist failure in SMEs in the state. SMEs have played and continued to play significant roles in the growth, development and industrialization of many economies in the whole world. In the case of Anambra State, SMEs have performed below expectation due to a combination of problems which range from attitude and habits of SMEs themselves to environmental factors, instability of governments and frequent government policy changes and somersaults. The major problem areas of SMEs in Anambra include management, access to finance, infrastructure, government policy inconsistencies and bureaucracy, environmental factors, multiple taxes and levies, access to modern technology, unfair competition, marketing problems, while non-availability of raw materials locally is the least problem.

The potentials and opportunities for SMEs in Nigeria to rebound and play the crucial role of engine of growth, development and industrialization, wealth creation, poverty reduction and employment creation are enormous. The realization of this requires a paradigm shift from laying lip service to a practical radical approach and focus on this all -important sector of the economy by the government realistically addressing the identified problems. While SMEs themselves need to change their attitude and habits relating to entrepreneurship development, the governments need to involve the SMEs in policy formulation and execution for maximum effect. There is also the dire need to introduce entrepreneurship education in our schools and within the business ecosystem.

Promoters of SMEs should thus ensure the availability or possession of managerial capacity and acumen before pursuing financial resources for the development of the respective enterprises.

This study will unveil the secret of business planning and the need for preparing a business plan in order to enhance the performance of SMEs in Anambra State.

Performance simply means how well or badly something is been done. The performance of Small and medium Enterprises (SMEs) is very crucial. This is because it is the backbone upon which every economy relies most for its well-being. Hence SMEs reduces the issue of unemployment, increases revenue generation, reduces poverty, and increases the standard of living of the citizen. SMEs play an important role as a breeding ground for entrepreneurs and a provider of solutions to 
address the problems of unemployment, job creation, innovation and long-term economic development (Eniola 2014). The performance of Small and Medium Enterprises in Anambra State seems to be below expectations. Upon this, this study seeks to find out the causes of poor performance of SMEs in the state and the remedies to the causes for effective performance of SMEs in Anambra state just as is obtainable in the states mentioned earlier.

\section{STATEMENT OF THE PROBLEM}

The operators/owners of Small and Medium Enterprises in Anambra State are faced with a lot of problems especially in the issues of lack of measures or value evaluation. They seem to be ignorant of the vital roles of measure evaluations in increasing business sustainability and revenue. Thus, they fail to put these variables into consideration in their initial business planning processes. Measures involve norms which should be maintained and monitored in order to guide the day to day activities of the enterprises in attainment of the expected income. Without it the operator(s) will keep doing whatever that pleases them without consideration of its consequences in the life of the business. Measures are taken in order to check-mate actions against expectations. Measures include avoidance of selling of substandard products. When poor quality goods are sold to customers, it affects the progress of such firm by leading to loss of customer(s) to other competitors for not satisfying their need; decreasing the firm's revenue; affecting the cash flow of such firm because the customers will return the product and demand back the cash they paid for such; and will make the firm to be stocked with inferior goods. This may eventually affect the capital of that business thereby affecting its continuity.

The Second measure is the issue of keeping daily records of the business. Some of the SMEs purchase goods without having the record in a purchase book. In the same way they sell without recording what was sold and the amount it was sold on daily basis. This makes it difficult for them to ascertain when they are overstocked with a particular product, the amount of revenue they have acquired, if there is progress or not, and when to expand or invest the money realized in other moving ventures. Another important challenge is punctuality. There is a saying that punctuality is the soul of business some of the SMEs operators/owners failed to recognize it. They feel that the business is theirs and they can be there at the time that pleases them. This habit affects the progress of the firm because some customers feel it is best to buy goods from the owner and not from the apprentice because customers believe that goods are sold at the right price when they purchase directly from the owner but purchasing from apprentice or shop attendant can make cost of the goods to be on the high side. Based on this, those SME owners that are guilty of such bad habit find it difficult to experience customer retention which affects the income of the firm. Also, customers need to be treated with care, but some of the SMEs owners/operators treat their customers with disrespect, forgetting that without the customers' patronage their business will collapse. They do not seem to understand that the customer is always right.

Operators/owners of SMEs in Anambra State do not seem to care about the impression they are making. Who do people say they are in terms of business operations? Do people speak negatively or positively about the way they carry out their businesses? Are they mostly known as people who are truthful in business, selling original items, selling at minimum cost, giving bonus for buying in large quantity or during festival period?

They do not seem to care that the behavior one exhibits in business negatively or positively affects the life of such enterprise. If the behavior is negative it scares away customers, but if it is positive it will not only sustain existing customers but draws new ones thereby sustaining the life of such enterprise. All these problems of SME operators in Anambra State have motivated the researcher in carrying out this study.

\section{OBJECTIVES OF THE STUDY}

The broad objective of this study is to establish the relationship between business planning and performance of SMEs operating in Anambra state. The specific objectives are:

1. To examine the relationship between benchmarking and earned income of the operators/owners of SMEs in Anambra State.

2. To ascertain the relationship between brand identity and deduction for goods returned to SMEs operators in Anambra State

3. To determine the relationship between accuracy of the action plan and discounts in SMEs in Anambra State.

\section{Research Questions}

The following questions guided the study:

1. To what extent has benchmarking influenced earned income of the operators/owners of SMEs in Anambra State?

2. To what extent has brand identity influenced deduction for goods returned to SMEs operators in Anambra State?

3. What is the relationship between accuracy of the action plan and discounts in SMEs in Anambra State

\section{Hypotheses}

The following alternative statements of assumption were put forward to help reach a verifiable conclusion on the stated objectives:

$\mathrm{Ha}_{1}$ Benchmarking has positive influence on the earned income of the operators/owners of SMEs in Anambra State. 
$\mathrm{Ha}_{2} \quad$ Brand identity has significant positive influence on the deduction for goods returned to operators of SMEs in Anambra State.

$\mathrm{Ha}_{3}$ There is significant positive relationship between accuracy of the action plan and discounts in SMEs in Anambra State

\section{SIGNIFICANCE OF THE STUDY}

This study will be beneficial to some personalities among which are Higher Institutions of learning, Government and its institutions, Business communities and researchers. Students participating in the activities of business planning - Development of business plan can become a new source of funding small business enterprise or give the students opportunities to be employed in firms or become business consultants.

Higher institutions of learning: this study will assist higher institutions in Anambra State in nurturing sound business planning idea for their students and exposing them to great business opportunities. This study will enlighten the institutions on how to design business plan and need for business planning to take care of the students concerned in order for them to become great employers in the SME environment.

Government and its institutions: the governments of every nation always want and look for solution(s) to her socio-economic problems. SMEs have been identified as an element in solving socio-economic issues bedeviling Nigeria which Anambra State is not an exception, and it is evident that SMEs in Anambra State face harsh challenges in the area of policy, economy and knowledge. The study will serve as an eye opener for the government to understand the area(s) SMEs in Anambra deserve her attention and such will ensure that adequate assistance/attention is given to the SMEs to encourage them for effective performance.

Researchers: It will serve as a reference material for future researchers. Also, the recommendations and area for further research put forward by this study will increase the interest of researchers in this area of study.

Business ecosystem: the outcome of this study will serve as a basis for business start-ups and existing businesses to understand the need to plan ahead before commencing business, as well as putting the plans into action (and evaluate the actions taken in order to overcome some of the challenges at hand and achieve positive performance like increased profitability).

\section{SCOPE OF THE STUDY}

Since this study is centred on "Business Planning and Performance of SMEs in Anambra State" the study focused on selected SMEs (traders business outlets) from the three Senatorial zones in Anambra State (Anambra North, Anambra South and Anambra Central). Anambra North, comprising of Awka North and South, Njikoka, Dunukofia, Anaocha, and Idemili North and South Local Government Areas; Anambra Central, is made up of Onitsha North and South, Ogbaru, Oyi,
Ayamelu, and Anambra East and West Local Government Areas; and Anambra South consisting of Orumba North and South, Aguata, Ihiala, Ekwusigo and Nnewi North and South Local Government Areas. The focus is to ascertain the relationship between benchmarking, brand identity, accuracy of the action plan and earned income, discounts, and deduction from returned goods.

\section{LIMITATIONS}

The researcher encountered setbacks and limitations due to fear and unco-operative attitude from the respondents. Some of the respondents refused to open-up and rejected the questionnaire due to ignorance and fear. The challenge was mitigated by counseling and convincing them of the benefit they will derive from the study and assuring them that it is not meant for increment in their tax rate. This prompted their assistance in completing the questionnaire and opening up to the researcher.

\section{METHODOLOGY}

\subsection{Research Design}

The study applied survey research design because it is one in which a group of people or items is studied collecting and analyzing data from only a few people or items considered to be representative of the entire group (Onyeizugbo, 2013).

\subsection{Sources of Data}

The study used both primary and secondary sources of data

\subsection{Area of Study}

The study was carried out in Anambra State. The focus of this study was limited to the three senatorial zones (Anambra North, Anambra South and Anambra Central) in Anambra State.

\subsection{Population of the study}

The population of this study comprised of the SMEs owners/managers of the selected SMEs from the three Senatorial zones in Anambra State. The reason for the concentration on the owner/manager is because the variables under study are core strategic functions of the SMEs. The SMEs were chosen because they are accessible in term of generating useful information for this research work. The population of the study is 1,504 Small and Medium Enterprises. (SMEDAN 2017).

Table 1.1 Population of the Study

\begin{tabular}{|c|c|}
\hline $\begin{array}{c}\text { SENATORIAL } \\
\text { ZONES }\end{array}$ & POPULATION \\
\hline Anambra Central & 416 \\
\hline Anambra North & 508 \\
\hline Anambra South & 580 \\
\hline Total Population & 1,504 \\
\hline
\end{tabular}

Source: SMEDAN 2017

\subsection{Sample and Sampling Technique}

Taro Yamane was used to determine the sample size. It is denoted by the formula below: 


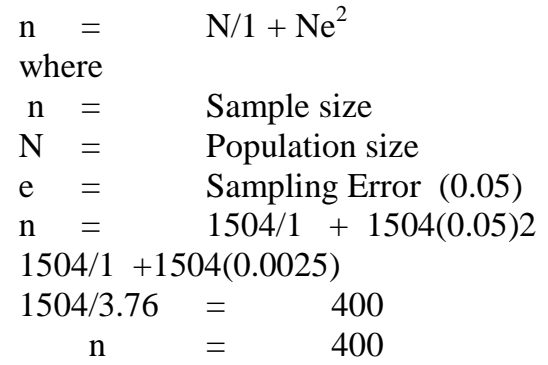

\subsection{Method of Data Collection}

Structured questionnaire was used in collecting data. The questionnaire was structured on a five Point Likert Scale (ranging from Strongly Agree $=5$, Agree $=4$, Disagree $=3$, Strongly Disagree 2 to Undecided $=1$ ) which covers the variables of the study as contained in the objectives of the study. Bowley's (1926) formula was used to determine the copies of the questionnaire to be distributed to each senatorial zone. The formula is: $\mathrm{Nh} \quad=\quad \mathrm{n}(\mathrm{nh}) \mathrm{N}$

Where $\mathrm{Nh}=$ Number of units to be distributed to each group

$\begin{array}{ll}\text { nh } & =\text { Number of respondents in each group } \\ \mathrm{n}= & \text { Total sample size } \\ \mathrm{N}= & \text { Total population size } \\ \text { That is, } & \end{array}$

$$
\begin{aligned}
& \mathrm{Nh}=400(416) / 1504=166400 / 1504=110.64 \\
& \text { approximately = } 111
\end{aligned}
$$

111 copies of the questionnaire were randomly distributed to Anambra Central Senatorial zone.

For Anambra South

$$
\begin{array}{cc}
400(580) / 1504=232000 / 1504 & =154.26 \\
\text { approximately }= & 154
\end{array}
$$

154 copies of questionnaire were randomly distributed to Anambra South Senatorial Zone.

For Anambra North:

$400(508) / 1504=203200 / 1504$

$=131.95$

approximately $=132$

132 copies of questionnaire were randomly distributed to Anambra North Senatorial Zone.

\subsection{Validity of the Instrument}

To ensure the validity of the instrument the researcher adopted the face and content validity procedure where the instrument (questionnaire)was given to research experts on the research subject to make the necessary inputs and corrections to ensure that the test instrument covered the objectives of the study.

\subsection{Reliability of the Instrument}

Spearman-Brown Coefficient was used to determine the reliability of the instrument. The formula is:

$$
\mathrm{r}_{\mathrm{t}}=\frac{2 \mathrm{r}}{1+\mathrm{r}}
$$

\section{Reliability Statistics}

\begin{tabular}{|lcl|l}
\hline Cronbach's Alpha & Part 1 & Value & .899 \\
& & N of items & Value \\
& Part 2 & N of items & $15^{\mathrm{a}}$ \\
& Total N of items & .950 \\
& & $15^{\mathrm{b}}$ \\
Correlation Between Forms & & 30 \\
Spearman-Brown Coefficient & Equal Length & .988 \\
& Unequal Length & .994 \\
Guttman Split-Half Coefficient & & .994 \\
& & .972
\end{tabular}

a. The Part 1 items are: Benchmarking, Brand identity, Accuracy of the Action Plan

b. The Part 2 items are: Earned income, Deductions for goods returned, Discounts

From the above $r=0.972$. This shows that there is a strong positive relationship between the variables.

\section{METHOD OF DATA ANALYSIS}

Pearson's Product moment Correlation Coefficient with the aid of (SPSS) was used to test the hypothesis to ascertain the nature of relationship that exists between the dependent and independent variables.
The correlation formula is given below:

r $\sum x y-\left(\sum x\right)\left(\sum y\right)$

Where :

$$
\frac{\mathrm{n}}{\sqrt{\left(\sum \mathrm{x}^{2}\right)-\left(\sum_{\mathrm{n}}\right)^{2}} \sqrt{\left(\sum y\right)^{2}-\left(\sum_{\mathrm{n}}\right)^{2}}}
$$

$\mathrm{r}=$ Correlation Coefficient

$\mathrm{x}=$ Dependent Variables

$y=$ Independent variables

$\mathrm{n}=$ Number of Scores

In this study, $r^{2}$ was used to determine the relationship between the sub-variables

\section{Decision rule:}

The decision rule was to accept the null hypothesis when the alpha value is greater than the probability values, otherwise reject it. 


\section{DATA PRESENTATION, ANALYSIS AND DISCUSSION OF FINDINGS}

This chapter is sub-divided into three sections as follows: Section 4.0 Analysis of the each Senatorial Zone; Section 4.1 presents descriptive statistics (univariate and multivariate properties); Section 4.2 presents the Analysis of questionnaire and test of hypotheses; and Section 4.3 presents the discussion of findings emanating from the study.

Analysis of SMEs in each Senatorial Zones

Specific Analysis

\begin{tabular}{|l|l|c|c|c|}
\hline S/N & \multicolumn{1}{|c|}{ Senatorial Zone } & No. Distributed & No. Returned & No. Analysed \\
\hline 1 & Anambra Central & 111 & 110 & 110 \\
2 & Anambra South & 154 & 152 & 152 \\
3 & Anambra North & 132 & 123 & 123 \\
& Total (Percentage) & $\mathbf{4 0 0}(\mathbf{1 0 0 \% )}$ & $\mathbf{3 8 5}(\mathbf{9 6 . 2 5 \% )}$ & $\mathbf{3 8 5}(\mathbf{9 6 . 2 5 \% )}$ \\
\hline
\end{tabular}

Source: Field Survey (2020)

\section{Descriptive Statistics}

Univariate Properties of Data

The univariate properties of the data, that is, mean, median, minimum. Maximum, standard deviation, skewness and kurtosis.

Table 4.2 Summary Statistics of Independent Variables

\begin{tabular}{|l|c|c|c|}
\hline & B & BI & AAP \\
\hline Mean & 16.91429 & 18.91948 & 21.11688 \\
Median & 14.00000 & 17.00000 & 21.00000 \\
Maximum & 25.00000 & 25.00000 & 25.00000 \\
Minimum & 8.000000 & 13.00000 & 11.00000 \\
Standard deviation & 6.696192 & 4.365020 & 2.948225 \\
Skewness & 0.182401 & 0.143425 & -0.449752 \\
Kurtosis & 1.318933 & 1.247447 & 1.971076 \\
Jarque-Bera & 47.46838 & 50.59100 & 29.96249 \\
Probability & 0.000000 & 0.000000 & 0.000000 \\
Sum & 6512.000 & 7284.000 & 8130.000 \\
Sum Sq. dev. & 17218.17 & 7316.504 & 333.740 \\
Observations & 385 & 385 & 385 \\
\hline
\end{tabular}

Source: E-views 9.0

The table presents the descriptive statistics of the independent variables of the study; the mean of Benchmarking (B) is 16.81 , which means that the average number of response as to Benchmarking within most of the Senatorial zones is 16.81 , the minimum value is 8 and the maximum number is 25 . The mean - Brand Identity (BI) is 18.91, which means that the average number of response as to brand identity within the senatorial zones is 18.91, the minimum value is 13 and the maximum number of those with good brand identity is 25. Accuracy of the Action Plan (AAP) the mean is 21.12, which means that the average number of response as to accuracy of the action plan is 21.12 , the minimum value is 11 and the maximum number of those who understands it is 25. This indicates that operators/owners of SMEs require the applications of these variables (benchmarking, good brand identity and accurate action plan in their daily business activities.

\section{Multivariate Properties of Data}

Table 4.3Correlation Matrix of Independent

Variables

\begin{tabular}{|l|c|c|c|}
\hline & B & BI & AAP \\
\hline B & 1.000000 & 0.843139 & 0.716784 \\
BI & 0.843139 & 1.000000 & 0.687134 \\
AAP & 0.716784 & 0.687134 & 1.000000 \\
\hline
\end{tabular}

Source: E-views 9.0

The table above presents the correlation matrix of the independent variables of the study.

Benchmarking is positively related to brand identity and accuracy of the action plan. Brand 
identity is positively related to benchmarking and accuracy of the action plan. Accuracy of the action plan is positively related to benchmarking and brand identity.

\section{Analysis of Research Questions and Test of} Hypotheses

Summary Statistics of Investigative Questions

\section{Research Question One:}

To what extend has benchmarking improved earned income of the operators/owners of SMEs in Anambra State?

4.4 Range of Scores for Benchmarking

\begin{tabular}{|llcl|}
\hline Range of Scores & $\mathbf{N}$ & Percentage & Remark \\
\hline $5-14$ & 63 & 12.4 & Poor score on Benchmarking \\
$15-25$ & 322 & 87.6 & Good scores on Benchmarking. \\
Total & $\mathbf{3 8 5}$ & $\mathbf{1 0 0}(\boldsymbol{\%})$ & \\
\hline
\end{tabular}

Source: Field Survey (2020)

Table 4.4 indicates the range of scores of respondents for benchmarking in the studied SMEs in Anambra State. The table revealed that 63 respondents $(12.4 \%)$ scored low ranging from 5 - 14 while 322 respondents $(87.6 \%)$ scored high on the variable ranging from $15-25$.

Table 4.6 Range of Scores for Earned Income

\begin{tabular}{|lccl|}
\hline Range of Scores & N & Percentage & Remark \\
\hline $5-14$ & 198 & 54.43 & Poor Scores on Earned Income \\
$15-25$ & 187 & 45.57 & Good Scores on Earned Income \\
Total & $\mathbf{3 8 5}$ & $\mathbf{1 0 0}(\boldsymbol{\%})$ & \\
\hline
\end{tabular}

Source: Field Survey (2020)

Table 4.6 indicates the range of scores of respondents for earned income in the studied areas. The table revealed that 198 respondents $(54.43 \%)$ scored high ranging from 5-14 while 187 respondents (45.57\%) scored low on earned income ranging from 15-25 in the studied SMEs in Anambra State.

Correlation Analysis for Benchmarking and Earned Income in the selected SMEs in the three Senatorial Zones in Anambra State.

Table 4.7 Correlation Analysis for Hypothesis One

\begin{tabular}{|lllc|}
\hline Correlation & & & \\
\hline \multirow{3}{*}{ Benchmarking (B) } & Pearson Correlation & 1 & EI \\
& Sig. (2-tailed) & & $.954^{* *}$ \\
& $\mathrm{~N}$ & 385 & .000 \\
Earned Income (EI) & Pearson Correlation & $.954^{* *}$ & 385 \\
& Sig. (2-tailed) & .000 & 1 \\
& $\mathrm{~N}$ & 385 & 385 \\
$* *$ Correlation is significant at the 0.01 level (2-tailed). & & \\
\hline
\end{tabular}

Source: SPSS Version 23.

Table 4.7 shows the correlation analysis done on benchmarking and earned income in the studied SMEs in the three Senatorial Zones in Anambra State. From the result, it showed that the Pearson's $r^{2}$ is .954 signifying a high and positive relationship between the variables.

\section{Test of Hypothesis}

Test of Significance for Hypothesis One

Ha: Benchmarking has significant improvement on earned income of the operators/owners of SMEs in Anambra State.

Table 4.8: Significance Test for Hypothesis One

\begin{tabular}{|lccll|}
\hline $\mathbf{N}$ & Cal. R & DF & Crit. r. & Remark \\
\hline 385 & 0.983 & 383 & 0.116 & Significant \\
\hline
\end{tabular}

Source: Field Survey (2020) 
Table 4.8 shows the result of significance done on hypothesis one in the selected SMEs in the Senatorial zones in Anambra State. The table showed that at 5\% level of significance and at 383 degrees of freedom, that the critical $\mathrm{r}$ is .116 while the calculated $\mathrm{r}$ is .983 . By the virtue of the calculated $\mathrm{r}$ being greater than the critical $r$, the research hypothesis is thus accepted and it stated that Benchmarking makes a significant improvement on earned income of the operators/owners of Small and Medium Enterprises in Anambra State.

\section{Research Question Two}

To what extent has brand identity influenced deduction for goods returned to SMEs operators/owners in Anambra State?

Table 4.9 Range of Scores for Brand Identity

\begin{tabular}{|lrcl|}
\hline Range of Scores & $\mathbf{N}$ & Percentage (\%) & Remark \\
\hline $5-14$ & 17 & 3.30 & Poor Scores on Brand Identity \\
$15-25$ & 83 & 96.70 & Good Scores on Brand Identity \\
Total & $\mathbf{3 8 5}$ & $\mathbf{1 0 0}(\boldsymbol{\%})$ & \\
\hline
\end{tabular}

Source: Field Survey (2020)

Table 4.9 shows the range of scores of respondents for Brand identity in the selected SMEs in the Senatorial zones in Anambra State. The table showed that 17 respondents (3.35) scored low ranging from 5 - 14 while 83 respondents (96.70\%) scored high on the variable ranging from 15-25 in the SMEs in Anambra State.

Table 4.10 Range of Scores for Deductions for Returned Goods

\begin{tabular}{|lccc|}
\hline Range of Scores & N & Percentage (\%) & Remark \\
\hline $5-14$ & 196 & 50.01 & Poor scores on deductions for returned goods \\
$15-25$ & 189 & 49.09 & Good scores on deductions for returned goods \\
Total & $\mathbf{3 8 5}$ & $\mathbf{1 0 0}(\boldsymbol{\%})$ & \\
\hline
\end{tabular}

Source: Field Survey (2020)

Table 4.10 shows the range of scores of respondents for deductions for goods returned to the operators/owners of the selected SMEs in Anambra State. The table revealed that 196 respondents $(50.01 \%)$ scored low ranging from 5-14 while 189 respondents (49.09\%) scored high on the variable ranging from 5-14.

Correlation Analysis for Brand Identity and Deductions for Goods Returned to the operators/owners of the selected SMEs in Anambra State.

Table 4.11 Correlation Analysis for Hypothesis Two

\begin{tabular}{|lllc|}
\hline \multicolumn{3}{c|}{ Correlations } & \\
\hline \multirow{3}{*}{ Brand Identity (BI) } & BI & DRG \\
& Pearson Correlation & 1 & $.882 * *$ \\
& Sig. (2-tailed) & & .000 \\
& $\mathrm{~N}$ & 385 & 385 \\
Deductions for Goods Returned (DRG) & Pearson Correlation & $.882^{* *}$ & 1 \\
& Sig. (2-tailed) & .000 & \\
& $\mathrm{~N}$ & 385 & 385 \\
$* *$ Correlation is significant at the 0.01 level (2-tailed). & & \\
\hline
\end{tabular}

Source: SPSS Version 23.

Table 4.11 showed the correlation analysis done on Brand identity and deductions for returned goods in the selected SMEs from the Senatorial Zones in Anambra State. From the result, it showed that the Pearson's $r^{2}$ is .882 meaning that a high and significant influence exists between the variables.

\section{Test of Significance for Hypothesis Two}

$\mathbf{H}_{2} \quad$ Brand identity has significant influence on deductions for goods returned to operators/owners of SMEs in Anambra State.

Table 4.12 Significance Test for Hypothesis Two

\begin{tabular}{|ccccc|}
\hline $\mathbf{N}$ & Cal. R & DF & Crit. R. & Remark \\
\hline 385 & 0.882 & 383 & 0.116 & Significant \\
\hline
\end{tabular}


Table 4.12 indicates the result for test of significance done on hypothesis two in the selected SMEs in Anambra State. The table showed that at 5\% level of significance and at 383 degrees of freedom, that the critical $\mathrm{r}$ is .116 while the calculated $r$ is .882. Because the calculated $r$ is greater than the critical $r$, the research hypothesis is therefore accepted and it is stated that Brand identity has significant influence on the deductions for goods returned to operators/owners of SMEs in Anambra State.

\section{Research Question Three}

What is the relationship between accuracy of the action plan and discounts in SMEs in Anambra State?

Table 4.13 Range of Scores for Accuracy of the Action Plan

\begin{tabular}{|c|c|c|}
\hline Range of ScoresN & Percentage (\%) & Remark \\
\hline $5-14$ & 0.60 & Poor scores on Accuracy of the Action Plan \\
\hline $15-25$ & 99.40 & Good scores on Accuracy of the Action Plan \\
\hline Total & $100(\%)$ & \\
\hline
\end{tabular}

Source: Field Survey (2020)

Table 4.13 indicated the range of scores of respondents for accuracy of the action plan in the selected SMEs in Anambra State. The table revealed that three (3) respondents $(0.60 \%)$ scored low while 382 respondents $(99.40 \%)$ scored high on the variable.

Table 4.14 Range of Scores for Discounts

\begin{tabular}{|lccc|}
\hline Range of ScoresN & \multicolumn{2}{c|}{ Percentage (\%) } & Remark \\
\hline $5-14$ & 180 & 46.75 & Poor scores on Discounts \\
$15-25$ & 205 & 53.25 & Good scores on Discounts \\
Total & $\mathbf{3 8 5}$ & $\mathbf{1 0 0}(\boldsymbol{\%})$ & \\
\hline
\end{tabular}

Source: Field Survey (2020)

Table 4.14 shows the range of scores of respondents for Discounts in the selected SMEs in the Senatorial Zones in Anambra State. The table showed that 180 respondents (46.75\%) scored low while 205 respondents $(53.25 \%)$ scored high on Discounts in the selected SMEs in Anambra State.

Correlation Analysis for Accuracy of the Action Plan and Discounts in the selected SMEs in Anambra State.

Table 4.15 Correlation Analysis for Hypothesis Three

\begin{tabular}{|llcc|}
\hline \multicolumn{3}{|c|}{ Correlations } \\
\hline AAP D & Pearson Correlation & 1 & $.727 * *$ \\
Accuracy of Action Plan (AAP) & Sig. (2-tailed) & 385 & .000 \\
& $\mathrm{~N}$ & $.727 * *$ & 385 \\
\multirow{2}{*}{ Discounts (D) } & Pearson Correlation & .000 & 1 \\
& Sig. (2-tailed) & 385 & 385 \\
$* *$ Correlation is significant at the 0.01 level (2-tailed) & & \\
\hline
\end{tabular}

Source: SPSS Version 23.

Table 4.15 shows the correlation analysis done on Accuracy of the Action Plan and Discounts in the selected SMEs in the Senatorial zones in Anambra State. The result showed that the Pearson's $r^{2}$ is .727 signifying a high and positive relationship between the two variables.

\section{Test of Significance for Hypothesis Three}

$\mathbf{H}_{3}$ : There is significant positive relationship between accuracy of the action plan and discounts in SMEs in Anambra State.

Table 4.16 Significant Test for Hypothesis Three

\begin{tabular}{|lcccl|}
\hline $\mathrm{N}$ & Cal. R & DF & Crit. r. & Remark \\
\hline 385 & 0.727 & 383 & 0.116 & Significant \\
\hline
\end{tabular}

Source: field Survey (2020) 
Table 4.16 shows the result of test of significance done on hypothesis three in the selected SMEs in Anambra State. The Table showed that at $5 \%$ level of significance and at 383 degrees of freedom, that the critical $\mathrm{r}$ is .116 while the calculated $r^{2}$ is .727 . By the virtue of the calculated $r$ being greater than the critical $r$, the research hypothesis that stated that there is significant positive relationship between accuracy of the action plan and discounts in Small and Medium Enterprises in Anambra State was accepted.

\section{DISCUSSION OF FINDINGS}

The results of the tests carried out from SMEs in the three Senatorial zones in Anambra State are discussed below. From the analysis of correlation for hypothesis one, it revealed that there is a high and positive relationship between benchmarking and earned income $\left(r^{2}=.954\right)$ in the studied enterprises. From the test of significance done, it revealed that the relationship is statistically significant as the observed coefficient was higher than the critical coefficient (at 5\% level of significance and at 383 degrees of freedom, critical $r=.116$ while calculated $\left.r^{2}=.983\right)$. This showed that benchmarking makes a significant improvement on earned income of the operators/owners of Small enterprises. This result is consistent with the results obtained by previous researchers such as Unam., Akinola, Olagbenia \& Aladeraji (2015) who stated that strategic management has significant effects on the profitability and operational performance of the selected manufacturing firms.

From the analysis of correlation between brand identity and deduction for goods returned to SMEs operators, the result revealed that a high and significant influence exists between brand identity and deductions for goods returned to the owners of SMEs $\left(r^{2}=.882\right)$. Testing the significance of the relationship observed showed that the relationship was Significant; it was not due to chance or error. This is because the calculated correlation coefficient was greater than the critical correlation coefficient at appropriate degrees of freedom and alpha level (at 5\% level of significance and at 383 degrees of freedom, the critical $r=.116$ while the calculated $r^{2}=.882$ ). This result signifies that brand identity has significant influence on the deductions for goods returned to operators/owners of small and medium enterprises. This is in line with the result obtained from previous research by Johanudin L., Nur S. R, and Noraslina M. (2015), who stated that brand image strengthens the understanding of what customers really want when choosing a product and influence their satisfaction; customers satisfaction helps to drive repeat business thereby increasing the profit of the firm.

The correlation analysis carried out on accuracy of the action plan and discounts (received and allowed) in Small Enterprises in Anambra State, the result showed that there is a high and positive relationship between accuracy of the action plan and discounts in SMEs $\left(\mathrm{r}^{2}=.727\right)$. The test of statistical significance of the relationship observed in the correlation analysis came out positive (at $5 \%$ level of significance and at 383 degrees of freedom, the critical $r=.116$ while the calculated $\left.r^{2}=.727\right)$. That is, the relationship was statistically significant. This finding aligns with that of Donkor \& Kwarteng (2018) who examined the interacting effect of market dynamism and strategic planning on the performance of Small and Medium Enterprises in Ghana. The findings revealed that a consistent application of strategic planning methodologies contributes to the advancement of SMEs performance in Ghana. It also indicated that market dynamism has a significant positive relationship with firm performance.

\section{SUMMARY OF FINDINGS, CONCLUSION AND RECOMMENDATIONS \\ Summary of Findings}

The following findings were made from the test of hypotheses carried out in the study:

1. Test of hypothesis one indicates that there is a strong positive and significant relationship between benchmarking and earned income $\left(r^{2}=0.954\right)$.

2. Test of hypothesis two indicates that there is a positive significant relationship between brand identity and deductions for goods returned $\left(r^{2}=0.882\right)$.

3. From the test of hypothesis three, it shows that there is a positive relationship between accuracy of the action plan and discounts $\left(r^{2}=0.727\right)$.

\section{CONCLUSION}

The research work concludes that Business planning plays a crucial role in determining the performance of SMEs. This is as a result of the positive relationship observed between: benchmarking and earned income; brand identity and deductions for goods returned; and accuracy of action plan and discounts in small and medium enterprises.

Since there is a positive strong relationship between decomposed variables of the independent and dependent variables then we concluded that there is a significant relationship between business 
planning and the performance of SMEs in Anambra State.

\section{Recommendations}

From the listed findings of the study the following recommendations were made respectively:

1. Since there is a strong positive and significant relationship between benchmarking and earned income. It is recommended that every small and medium enterprises needs to embrace business planning for effective performance. Find out the enterprises weaknesses and identify the secret behind other progressing enterprises in the same line of business and apply such in their own business in order to sustain the life of their businesses and achieve increased income.

2. Based on the finding that there is a positive significant relationship between brand identity and deductions for goods returned. There is need for the operators/owners of SMEs to understand that maintaining good brand identity (image) is very vital to the life of the business. SMEs operators/owners need to understand that creating good image/identity depends on their ability to supply their customers with genuine products to satisfy their taste. This will enhance positive brand identity (image) of the enterprise, enhance customers' satisfaction, attract new customers and pave way for customers' retention. Therefore, the operators of SMEs need to avoid selling of substandard products to customers and ensure that they supply exactly what customers demanded, always treat customers with fairness in order to create a good image of the enterprise and minimize the existence of returned goods.

3. There is a significant positive relationship between accuracy of the action plan and discounts. From this finding every organization needs to be involved in business planning which will aid them identify the right strategic measures to apply in their day to day business affairs. It will assist them in the collection of useful or needed data from other organization, perfectly analyse the data and present the best business proposal that can lead the organization to achieve positive results/increase productivity; in order to boost their ability to receive discounts from their suppliers as well as allow discounts to their customers for increased turnover and good business performance. Equally, owners of SMEs need not neglect keeping records of their daily business transactions because it will help understand if the business is progressing or not. SMEs owners needs to be punctual always, this will help them attain to their customers and not leaving them to the mercy of their apprentices/office attendants.

Equally, there is need for the owners/operators of SMEs to ensure that the business plans are formulated and strictly adhered to achieve the desired goal.

Also, Stakeholders in SMEs should be involved in policy formulations and implementation for them to be effective and yield expected results.

Thus, in order to achieve the vital roles of SMEs (economic growth, employment generation, and poverty reduction etc) in the Anambra State there must be measures set out by the owners/operators to monitor and maintain the daily operations of their respective businesses. These measures will enable them to sustain the life of the businesses and achieve the forecasted objective(s).

Finally, to achieve a sustainable business (better business) and increased income, there must be better regulations, better products and services.

\section{Contributions to Knowledge}

The study's contributions to knowledge is in the areas of exposing the relationship between benchmarking and earned income; brand identity and deduction for goods returned; and accuracy of the action plan and discounts. Hence such findings have not been observed in the enterprises in Anambra State before, it is a tool to be used by operators/owners of SMEs to understand the need to improve their brand identity, identify progressive firms to benchmark, and improve their action plan in order to perform better amidst competitive market environment.

\section{Area for further studies}

Since little work was carried out on material resources and growth of SMEs further studies should be carried out to ascertain the relationship between material resources and growth of Small and Medium Enterprises. This is to assist the owners/operators of Small and Medium Enterprises acquire in-depth understanding of the intricacies of business planning and performance of their businesses. 


\section{REFERENCES}

1. Ashe-Edmunds, S. (2016). Benefits of a Business Plan. Accessed on 15 March, 2019 . Available at http://smallbusiness.chron.com

2. Ayozie, D.; Obere, J.;Umukoro, F. \&Ayozie, V.(2013).Small and Medium Scales Enterprises in Nigeria the Marketing Interface. Global Journal of Management and Business Research (E) Vol. XIII. Issue IX Version 1 2013.

3. Donkor, J.; Donkor G. \& Kwarteng, C. (2018).Strategic Planning and Performance of SMEs in Ghana. Asia Pacific Journal of Innovation \& Entrepreneurship Vol. 12 issue 1. Retrieved from www.google.com on $7^{\text {th }}$ November, 2019.

4. Eniola, A, \& Entebang, H. (2014). SME Firms Performance in Nigeria: Competitive Advantage and its Impact. International Journal of Research Studies in Management. Vol. 1 No. 1 www.google.com . Assessed on $17^{\text {th }}$ July, 2019

5. Gleeson (2016): Five Reasons You Need a Business Plan. Bplans.co.uk/starting-a-business. Retrieved from www.google.com on $15^{\text {th }}$ October, 2020.

6. Johanudin, L.; Nur, S. \& Noraslinda, M. (2015): Brand Image Towards Customer Satisfaction in Malaysian Hotel Industry. $6^{\text {th }}$ International Research Symposium in Service Management, IRSSM-6 2015. Retrieved from www.chron.com on $20^{\text {th }}$ February, 2020.

7. Onyeizugbe, C. U. (2013). Practical Guide to Research Methodology in Management. Good Success Press, Onitsha

8. SMEDAN (2017): National Survey of Micro Small and Medium Enterprises (MSMEs)- National Bureau of Statistics pg. 67.

9. Unam, M.; Akinola, G...; Olagbenia, P.\& Aladeraji, O. (2015): $\quad$ Strategic $\quad$ Management and Firm Performance: A study on Selected Manufacturing Companies in Nigeria. International Academic Research Journal of Business \& Technology 2015. Retrieved from www.jarjournal.com accessed on the $24^{\text {th }}$ October, 2020. 